\title{
ENTELEKTÜEL SERMAYENIN İŞLETMELERDE BİR BÜTÜN OLARAK ÖLÇÜLMESİ: BIST 30 UYGULAMASI
}

****

\section{MEASUREMENT OF INTELLECTUAL CAPITAL AS A WHOLE IN THE ENTERPRISE: BIST 30 APPLICATION}

\author{
Arş. Gör. Emre Esat TOPALOĞLU \\ Mersin Üniversitesi \\ İIBF, İşletme Bölümü \\ emresatopal@ hotmail.com
}

Öğr. Gör. Özlem KARAKOZAK

Nevşehir Hacı Bektaş Veli Üniversitesi

Gülşehir MYO, Bankacılık ve Sigortacılık Bölümü

ozakara86@gmail.com

\section{Öz}

Çalışmada, Borsa İstanbul 30 Endeksi’nde faaliyet gösteren 18 şirketin 2010-2015 dönemindeki entelektüel sermaye değerlerini ölçmek ve endeksteki şirketleri sahip olduklarl entelektüel sermaye değerleri doğrultusunda sıralamak amaçlanmıştır. Bu bağlamda, entelektüel sermayeyi işletmelerin finansal verileri doğrultusunda

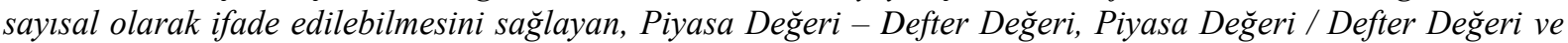
Tobin's q Oranı yöntemleri ile ölçülerek yıl ve yöntem bazında analiz edilmiştir. Analiz neticesinde elde edilen bulgulara göre hizmet sektöründe yer alan şirketlerin, sahip olduklart yüksek düzeyde entelektüel değere göre endeks içerisinde üst sıralarda yer aldiğı belirlenmiştir. Buna karşın holdinglerin ise düşük seviyede entelektüel sermaye değerleri ile sıralamada sonlarda yer aldıklarl görülmüştür. Ayrıca çalışmada, Tobin's q Oranı, Piyasa Değeri / Defter Dĕgeri ve Piyasa Dĕ̆eri - Defter Değeri yöntemlerinin paralel sonuçlar verdiği de tespit edilmiştir.

Anahtar Kelimeler: Entelektüel Sermaye, Tobin's q, BIST 30

\begin{abstract}
In the study, Borsa Istanbul is located 18 companies operating in 30 index. Study in the company of the 20102015 period is intended to measure intellectual capital values and to sort index value of intellectual capital in the company in line with what they have. Market Value to measure intellectual capital - Book Value, Market Value / Book Value and Tobin's q Ratio method is used. According to the analysis findings; Located in the services sector companies, with a high level that they were determined to get higher rankings in the index based on intellectual values. However, if they take place at the end of the holding it has been seen in the rankings with a low level of intellectual capital values.
\end{abstract}

Keywords: Intellectual capital, Tobin q, BIST 30 


\section{GIRISS}

Günümüzde teknolojik yenilikler ile bilgi akışının artması, bilginin küreselleşmesi, entelektüel sermaye kavramının oluşmasında büyük katkı sağlamıştır. Özellikle küreselleşme, maddi varlıkların yanı sıra maddi olamayan (değer yaratan) varlıkların, yani bilginin de önemli bir faktör olarak görülmesini sağlamıştır.

Entelektüel sermaye, işletmelerde maddi ya da finansal varlıklardan daha değerli olarak kabul edilmekte ve işletmelerin görünmez aktiflerinin yönetimi olarak algılanmaktadır (Yıldız, 2010).

Entelektüel sermaye, beceri ve deneyime dayandırılmış bilginin oluşturduğu bir unsur olarak ifade edilebileceği gibi literatürde; "Kâra dönüştürülebilen bilgi", bir organizasyonun sahip olduğu görünür varlıklar (patent hakları, lisanslar, teknolojiler) ve görünmez varlıklar (çalışanların tecrübeleri, bilgi ve birikimleri, üretkenlikleri) toplamı" (Bölükbaşı, 2014), kendini sürekli yenileyen "bilgi ekonomisi” (Zor \& Cengiz , 2013), gibi birçok şekilde tanımlanmaktadır.

Entelektüel sermaye ile ilgili önceden yapılan çalışmalar incelendiğinde entelektüel sermaye tanımında olduğu gibi entelektüel sermayeyi oluşturan unsurların da birbirinden farklı tanımlamaları bulunmaktadır. Bu farklılığının nedeni olarak tanımlamalardaki kişisellik yani tanımı yapan kişinin önemsediği ve ilgi duyduğu alanların farklılaşması olarak gösterilebilir. Temelde literatürde entelektüel sermaye unsurları; yapısal sermaye, müşteri sermayesi ve insan sermayesi olarak üç şekilde ayrılmaktadır. Bontis (1998), çalışmasında entelektüel sermaye unsurlarını ve esaslarını aşağıdaki şekil yardımıyla göstermiştir.

Şekil 1: Entelektüel Sermaye Unsurları (Bontis, 1998)

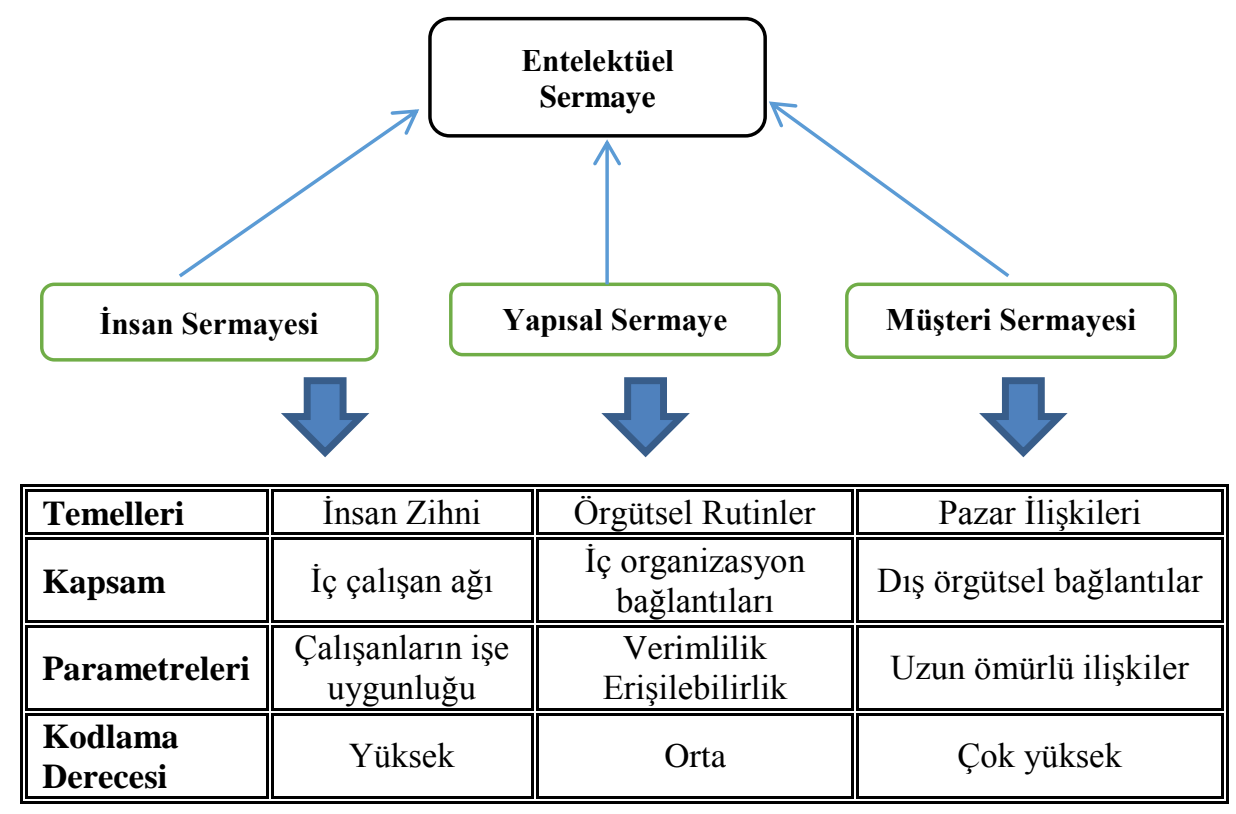

Bontis (1998), entelektüel sermaye unsurlarını üç temel grup altında toplamış ve her bir unsurun dayandığ 1 temelleri, kapsamı ve parametrelerini ortaya koymuştur. Ana unsuru insan zihni, parametreleri ise işe uygunluk olarak tanımlanan insan sermayesi; bireysel olarak kişinin kalıtsal özellikleri, eğitimi, tecrübesi, günlük hayat ve çalışılan kurum hakkındaki tutum ve davranışlarının bir bütünü olarak tanımlanabilir. Yapısal sermaye; işletme faaliyetlerindeki tüm organizasyon bağlantıları, süreç ve yöntem bilgileri ile kültür ve stratejilerine ilişkin deneyimlerden oluşmaktadır. Yapısal sermaye "insan sermayesini düzenleyen, yetkilendiren, destekleyici alt yapı" olarak da ifade edilmektedir (Demir \& Demirel, 2011).

Entelektüel sermaye unsurlarından müşteri sermayesi, işletmenin dış organizasyon bağlantılarındaki bağlılık, işletme bilinirliği, dağıtıcı ve toptancılarla olan ilişkileri v.b bağlantıları 
kapsar ve işletme için değer yaratabilecek işletme dışı tüm taraflarla ilgilidir (Çetin, 2005). Müşteri sermayesini uzun ömürlü ilişkiler üzerine kuran Bontis (1998)'in yanı sıra (Stewart, 1997), işletmelerin yeni müşteriler aramak yerine müşsterilerle organik ilişkiler kurmanın ve marka sadakati oluşturarak onu korumanın çok daha karlı olduğunu ifade etmektedir.

\section{ENTELEKTÜEL SERMAYENIN BİR BÜTÜN OLARAK ÖLÇÜLMESİ}

İşletmelerde maddi olmayan varlıkların yönetilmesinde ilginin entelektüel sermaye üzerine yoğunlaşması sonucunda entelektüel sermayenin ölçülmesine yönelik çok sayıda yöntem geliştirilmiştir. Luthy (1998) ve Williams (2000) çalışmalarında entelektüel sermayeyi ölçme yöntemlerini dört ana başlık altında toplamışlardır. Bunlar; doğrudan entelektüel sermaye yöntemleri, piyasa değeri yöntemi, aktiflerin karlılığı yöntemi (ROA), Puan kartı yöntemidir. Çalışma kapsamında finansal temele dayandırılan, entelektüel sermayeyi bir bütün olarak ölçen piyasa değeri yöntemi kullanılmıştır. Piyasa değeri yöntemi, bir işletmenin piyasa değeri ile özsermaye değeri arasındaki farkı maddi olmayan varlıklarının değeri ya da entelektüel sermaye olarak hesaplamaktadır (Jurczak, 2008). Piyasa Değeri Defter Değeri Oranı, Piyasa Değeri Defter Değeri Farkı Yöntemi, Tobin's q Oranı ve Hesaplanmış Maddi Olmayan Değer yöntemi piyasa değeri yönteminin içinde yer almaktadır. Ülkemizde de işletmeyi bir bütün olarak ele alıp finansal açıdan entelektüel sermayeyi ölçen çalışmalar bulunmaktadır. Kendirli, vd. (2015), "Hesaplanmış Maddi Olmayan Değer Yöntemi" kullanılarak Marmara bölgesinde bulunan, çimento sektöründe faaliyet gösteren 5 firmanın entelektüel sermayesini hesapladıkları çalışmalarında; 2010-2015 yılları arası araştırma kapsamındaki firmaların entelektüel sermaye açısından güçlü oldukları sonucuna ulaşılmıştır. Hizmet üreten işletmeler açısından entelektüel sermayeyi, Hesaplanmış Maddi Olmayan Değer Yöntemini kullanarak belirlemeye çalışan Bölükbaşı (2014), uygulamada Borsa İstanbul'da işlem gören sigorta şirketlerini kullanmıştır. 2008 küresel kriz ve sonrası etkilerinin ölçüldüğü çalışmada; Anadolu Hayat ve Emeklilik şirketinin insan, yapısal ve müşteri sermayesini rakiplerine göre çok daha iyi yönettiği görülmektedir. Anadolu Hayat ve Emeklilik şirketinin entelektüel sermaye değeri 390.079.880 TL olarak hesaplanmış ve sıralamada birinci olarak yer almıştır. Yıldız (2011) çalışmasında; Piyasa Değeri Defter Değeri Oran1, Piyasa Değeri Defter Değeri Fark1 ve Entelektüel Sermaye Unsurların (insan sermayesi, yapısal sermaye ve müşteri sermayesi) Algısal Ölçümü Yöntemleri kullanılarak bankacılık sektöründe entelektüel sermayeyi belirmeye çalışmıştır. Araştırmanın sonucunda, her üç yöntemde de Türkiye Garanti Bankası, Akbank, Türkiye İş Bankası ve Yapı ve Kredi Bankası'nın entelektüel sermayesi üst sıralarda iken Şekerbank, Tekstil Bank, Türk Ekonomi Bankası ve Alternatif Bank'ın entelektüel sermayesi alt sıralarda yer aldığı gözlenmiştir. Entelektüel sermayeyi işletme bazında ölçen bir diğer çalışma Şaban ve Uzay (2003)'e aittir. Çalışmada, Hesaplanmış Maddi Olmayan Değer Yöntemi kullanılarak mobilya sektöründe faaliyet gösteren yedi firmaya ait Entelektüel Sermaye değerleri hesaplanmış, birbirleriyle karşılaştırılmış ve entelektüel sermaye değerleri ile firmaların defter değerleri ve net aktif toplamları arasındaki oransal ilişkiler belirlenmiştir. Çalışma kısıtları gereğince 5 firma için entelektüel sermaye hesaplanmış ve karşılaştırılmıştır. Araştırma kapsamındaki tüm firmaların, entelektüel sermayelerini artırmaları gerektiği sonucuna varılmıştır.

Entelektüel sermayeyi diğer yöntemlere göre finansal olmayan bir açıdan inceleyen insan sermayesi, yapısal sermaye ve müşteri sermayesi unsurlarını inceleyerek entelektüel sermayeyi unsurlar bazında ölçen yöntemler de bulunmaktadır. Bu yöntemler; Bontis'in Entellektüel SermayePerformans Modelini dikkate alan algısal ölçüm, Skandia Klavuzu, Teknoloji Simsarı yöntemi, Dengeli Puan Kartı yöntemi, Entelektüel Katma Değer Katsayısı, Maddi Olmayan Varlıklar Göstergesi, Entelektüel Sermaye Endeksi ve Bilgi Bilançosu gibi yöntemlerdir (Bontis, 1998), (Bölükbaşı, 2014), (Yıldız, 2010), (Çıkrıkçı \& Daştan, 2002)

$\mathrm{Bu}$ çalışmada entelektüel sermaye değerleri, şirket bazında ve finansal değerler esas alınarak kullanılan, Piyasa Değeri - Defter Değeri (PD-DD), Piyasa Değeri / Defter Değeri (PD/DD) ve Tobin's q Oranı (TQ) yöntemleri ile ölçülmüştür. $\mathrm{Bu}$ yöntemler, şirketlerin finansal verileri doğrultusunda ölçülen ve sayısal olarak ifade edilebilen entelektüel sermaye değerlerini vermektedir. Ancak elde edilen bulguların, genel olarak şirketlerin sahip oldukları entelektüel sermaye varlıklarının 
yanı sıra bu varlıkları kullanabilme ve bu varlıklardan faydalanabilme gücünü de gösterdiği düşünülmektedir.

\subsection{Piyasa Değeri - Defter Değeri Oranı ve Farkı Yöntemi}

Entelektüel sermayenin en yaygın bilinen göstergesi olarak kullanılan bu yöntem işletmenin piyasa değerinin defter değerine oranıdır. Firmanın dolaşımdaki hisse senetlerinin alabileceği minimum değeri göstermektedir (Çetin, 2005). Kolay hesaplanabilir olması ve verilere rahat ulaşılması nedeniyle yaygın olarak kullanılmaktadır. Tek kısıt borsada hisse senetleri işlem gören işletmeler için uygulanabilmektedir (Çıkrıkçı \& Daştan, 2002)

Entelektüel sermayenin oran olarak ifade edildiği PD/DD oranı yöntemi; Entelektüel Sermaye= Piyasa Değeri / Defter Değeri, bu hesaplamada bulunan entelektüel sermaye değeri, işletmenin geçmiş yıl verileri ya da sektör ortalamaları ile karşılaştırılarak daha anlamlı bilgiler elde edilebilmektedir (Uzay \& Savaş, 2003).

Bir şirketin Piyasa Değeri / Defter Değeri oranının yüksek olması, entelektüel sermaye değerinin de yüksek olduğu anlamına gelmektedir. Bir önceki yöntemde entelektüel sermaye değeri tutar olarak gösterilirken, bu yöntemde entelektüel sermaye değeri oransal olarak ifade edilebilmektedir. Bu bağlamda Piyasa Değeri / Defter Değeri oranının şirketlerin entelektüel sermaye performanslarını yansıttığı söylenebilir. Bu durum da aynı endeks içerisinde yer alan ve farklı sektörlerde faaliyet gösteren şirketler arasında, geçmiş yıllara ilişkin kıyaslama yapabilme imkânını vermektedir (Stewart, 2000: 300; Demirkol, 2007: 87).

Entelektüel sermayeyi ölçmede kullanılan diğer yöntem 'Piyasa Değeri - Defter Değeri Farkı Yöntemi'dir. Temel mantığı, firmanın entelektüel sermayenin firmanın piyasa değeri ile defter değeri arasındaki fark yoluyla hesaplanmasıdır (Yıldız, 2010). Piyasa Değeri - Defter Değeri arasındaki fark, şirketin finansal tablolarında görünmeyen ancak şirket değerinin bir kısmını oluşturan entelektüel sermayenin yaklaşık değerini ifade etmektedir. Bu yöntemde entelektüel sermaye tutar olarak hesaplanmaktadır (Kendirli, Akgün, \& Özçetin, 2015).

\subsection{Tobin q Oranı}

Bir işletmenin sahip olduğu borç ve özkaynaklarının piyasa değerinin cari yerine koyma maliyetine oranına Tobin's q oranı denilmektedir. Nobel ödüllü ekonomist James Tobin tarafindan geliştirildiği için literatüre Tobin'nin q'su olarak geçmiştir (Brealey, Myers , \& Marcus, 2007).

Tobin's q yöntemi Piyasa Değeri/Defter Değeri yöntemine benzemekte fakat bu yöntemden faklı olarak defter değeri yerine varlığın yerine koyma maliyetini kullanmaktadır. Entelektüel sermayeyi ölçmek için kullanılan yöntemlerden birisi olan Tobin's q genellikle teknoloji ve insan sermayesine yönelik işletmelerde yüksek çıkmaktadır (Bontis, 1998).

$\mathrm{Bu}$ yöntemde işletme varlıklarının piyasa değerini varlıkların yerine koyma maliyetine bölünmesiyle reel getiri hesaplanmaktadır. Yatırımın reel getirisinin yükselmesi ile q değeri artmakta düşmesi sonucu q değeri azalmaktadır (Ercan \& Öztürk, 2003). Bu durumda işletmenin varlıklarının yerine koyma maliyeti, işletmenin piyasa değerinden düşük ise, diğer ifade ile q değeri 1'den büyük ise işletmenin aynı sektör işletmelerine göre daha fazla reel getiri elde ettiği anlamına gelmektedir. q değerinin 1'den küçük olması durumunda ise, işletmenin varlık bazında entelektüel sermayeye sahip olmadığı ve varlıkların getiri düzeylerinin düşük olduğu anlaşılmaktadır (Acar \& Dalgar, 2005). Ölçüt olarak kabul edilen Tobin's q değeri, işletmenin sahip olduğu fakat benzer işletmelerin sahip olmadığ maddi olmayan varlıkları yani entelektüel sermayeyi ifade etmektedir. Dolayısıyla, Tobin's q oranı yöntemi, bir önceki yöntemde olduğu gibi aynı endekste ve farklı sektörlerde faaliyet gösteren şirketlerin maddi olmayan varlıklarının yani entelektüel sermaye değerlerinin belirlenmesinde ve yıllar itibariyle karşılaştırılmasında kullanılabilmektedir. 


\section{ARAŞTIRMANIN AMACI}

Araştırmada, Borsa İstanbul 30 Endeksi'nde faaliyet gösteren şirketlerin entelektüel sermayelerinin, şirket değerinde yarattığı etkiyi ortaya çıkarmak ve şirketler üzerindeki etkisini incelemek amaçlanmıştır. Ayrıca çalışmada, endekste yer alan şirketlerin sahip oldukları entelektüel sermaye değerlerine göre, yıl bazında sıralamalarını da gerçekleştirmek hedeflenmiştir. Bu bağlamda, Borsa İstanbul 30 Endeksi'nde işlem gören şirketlerin entelektüel sermaye değerleri ölçülerek, endeks içerisindeki konumları karşılaştırılmıştır. Böylelikle farklı sektörlerde yer alan şirketlerin entelektüel sermayeleri finansal olarak ortaya koyulmuştur.

\section{ARASTTIRMANIN KAPSAMI}

Araştırma, 2010-2015 yılları arasında Borsa İstanbul 30 Endeksi'nde devamlı olarak faaliyet gösteren 18 şirketi ve bu şirketlere ilişkin verileri kapsamaktadır. Çalışma kapsamında analize dâhil edilen şirketler, aşağıda Tablo 1'de gösterilmektedir.

Tablo 1: Analiz Kapsamında İncelenen Şirketler

\begin{tabular}{|c|c|}
\hline BIST KODU & ŞİRKET ÜNVANI \\
\hline 1. AKBNK & AKBANK T.A.Ş. \\
\hline 2. ARCLK & ARÇELIKK A.Ş. \\
\hline 3. DOHOL & DOĞAN ŞİRKETLER GRUBU HOLDİNG A.Ş. \\
\hline 4. EREGL & EREĞLİ DEMİR VE ÇELIKK FABRIKKALARI T.A.Ş. \\
\hline 5. GARAN & TÜRKIYE GARANTİ BANKASI A.Ş. \\
\hline 6. HALKB & TÜRKIYYE HALK BANKASI A.Ş. \\
\hline 7. ISCTR & TÜRKIYYE İŞ BANKASI A.Ş. \\
\hline 8. $\mathrm{KCHOL}$ & KOÇ HOLDİNG A.Ş. \\
\hline 9. KRDMD & KARDEMİR KARABÜK DEMİR ÇELİK SANAYİ VE TİCARET A.Ş. \\
\hline 10. РETKİM & PETKİM PETROKIMMYA HOLDİNG A.Ş. \\
\hline 11. SAHOL & HACI ÖMER SABANCI HOLDİNG A.Ş. \\
\hline 12. SISE & TÜRKIYYE ŞISSE VE CAM FABRIKKALARI A.Ş. \\
\hline 13. TCELL & TURKCELL İLETIŞİM HİZMETLERİ A.Ş. \\
\hline 14. THYAO & TÜRK HAVA YOLLARI A.O. \\
\hline 15. TTKOM & TÜRK TELEKOMÜNIKASYON A.Ş. \\
\hline 16. TUPRS & TÜPRAŞ-TÜRKIYYE PETROL RAFINERİLERİ A.Ş. \\
\hline 17. VAKBN & TÜRKIYE VAKIFLAR BANKASI T.A.O. \\
\hline 18. YKBNK & YAPI VE KREDİ BANKASI A.Ş. \\
\hline
\end{tabular}

Kaynak: www.kap.org.tr

\section{ARASTTIRMANIN YÖNTEMI}

Çalışmada entelektüel sermayenin işletme bazında ölçülmesi için kullanılan yöntemlerden ilki ve en basit olanı, Piyasa Değeri - Defter Değeri'dir. Şirketin piyasa değeri ve finansal sermayeyi ifade eden defter değeri arasındaki ilişkiyi gösteren bu yöntem, şirketin piyasa değerinin, defter değerini aşan kısmının tutar olarak entelektüel sermaye değeri olduğu esasına dayanmaktadır (Uzay \& Savaş, 2003) (Ercan \& Öztürk, 2003). Bu bağlamda bir şirketin entelektüel sermayesi aşağıdaki formül ile hesaplanmaktadır.

\section{Entelektüel Sermaye $=$ Piyasa Değeri - Defter Değeri $($ Finansal Sermaye $)$}

Şirket bazında entelektüel sermayenin ölçümünde kullanılan bir diğer yöntem, Piyasa Değeri / Defter Değeri'dir. Bu yöntem, şirketin piyasa değerinin defter değerine bölünmesi suretiyle 
bulunmaktadır. $\mathrm{Bu}$ doğrultuda bir şirketin entelektüel sermayesi aşağıdaki formül ile hesaplanmaktadır.

\section{Entelektüel Sermaye $=$ Piyasa Değeri $/$ Defter Değeri (Finansal Sermaye)}

Çalışmada, şirket bazında entelektüel sermayenin ölçümünde kullanılan son yöntem, Tobin's q Oranı'dır. Yöntemde, şirketin sahip olduğu varlıklarının piyasa değerinin, bu varlıkları yerine koyma maliyetini aşan kısmı, entelektüel sermaye olarak ifade edilmektedir.

Tobin's q Oranı'nın hesaplanmasına ilişkin çeşitli uygulamalar olmakla birlikte, Türkiye'deki verilerin niteliği ve hesaplama zorluğu göz önüne alındığında Tobin's q oranı, aşağıdaki formül yardımıyla hesaplanabilmektedir (Chung \& Pruitt, 1994) (Dey \& Chauhan, 2009).

\section{Entelektüel Sermaye $=($ Piyasa Değeri + Toplam Yabancı Kaynak $) /$ Toplam Aktif}

\section{ARAȘTIRMANIN SINIRLARI}

Her araştırmada olduğu gibi bu çalışmada da bir takım sınırlamalar söz konusudur. Çalışma, Borsa İstanbul 30 Endeksi'nde 2010-2015 yılları arasında sürekli olarak faaliyet gösteren 18 şirketi kapsamaktadır. Ayrıca, 2008 yılında başlayan ve 2009 yılı sonuna kadar süren küresel mali krizin olası etkileri göz önüne alınarak analiz dönemi, 2010 yılı öncesini kapsamamaktadır.

\section{ARAŞTIRMANIN BULGULARI VE DEĞERLENDİRILMESİ}

Araştırmada, Borsa İstanbul 30 Endeksi'nde faaliyet gösteren şirketlerin, 2010-2015 dönemine ait entelektüel sermaye değerleri ortaya koyulmaya çalışılmıştır. Bu bağlamda şirketlerin entelektüel sermayeleri, TQ, PD/DD ve PD-DD yöntemleri ile ölçülmüştür. Yapılan analiz sonucunda elde edilen bulgular, yıl bazında incelenmiş ve her yönteme göre ayrı ayrı değerlendirilmiştir. BIST 30 şirketlerinin entelektüel sermaye değerleri aşağıdaki tablolarda her yıl için ayrı ayrı gösterilmiştir.

Bir şirketin piyasa değerinin defter değerine oranının yüksek olması, o şirketin entelektüel sermaye değerinin de yüksek olduğu anlamına gelmektedir. Ayrıca şirketin sahip olduğu varlıklarının piyasa değerinin, bu varlıkları yerine koyma maliyetini aşması da, o şirketin yüksek düzeyde entelektüel sermaye varlığına sahip olduğuna işaret etmektedir. Bu bağlamda bir şirketin yüksek değerde entelektüel sermaye varlıklarına sahip olabilmesi için TQ oranının ve PD/DD'nin 1'den yüksek olması ve PD-DD arasındaki farkın da pozitif olması gerekmektedir.

Tablo 2'de, BIST 30 Endeksi'nde faaliyet gösteren şirketlerin TQ, PD/DD ve PD-DD yöntemleri ile ölçülmüş 2010 yılı entelektüel sermaye değerleri yer almaktadır. 
Tablo 2: 2010 Y1lı için Entelektüel Sermaye Değerinin İșletme Bazında Ölçülmesi

\begin{tabular}{|c|c|c|c|c|c|}
\hline Sirketler & TQ & Sirketler & $\underline{\text { PD/DD }}$ & Sirketler & $\begin{array}{l}\underline{\text { PD-DD }} \\
\underline{\text { Bin TL })} \\
\end{array}$ \\
\hline 1. SISE & 2,2687 & 1. TTKOM & 3,6844 & 1. TTKOM & 16.575 .243 \\
\hline 2. TTKOM & 2,0977 & 2. SISE & 3,4628 & 2. GARAN & 16.412 .320 \\
\hline 3. YKBNK & 1,1992 & 3. YKBNK & 2,5554 & 3. AKBNK & 16.372 .406 \\
\hline 4. TCELL & 1,9017 & 4. TUPRS & 2,4778 & 4. TCELL & 13.611 .348 \\
\hline 5. TUPRS & 1,4142 & 5. TCELL & 2,4180 & 5. YKBNK & 12.859 .302 \\
\hline 6. PETKİM & 1,3282 & 6. HALKB & 2,1996 & 6. HALKB & 8.930 .320 \\
\hline 7. ARCLK & 1,2544 & 7. GARAN & 1,9988 & 7. ISCTR & 7.736 .031 \\
\hline 8. HALKB & 1,1224 & 8. AKBNK & 1,9122 & 8. TUPRS & 5.765 .025 \\
\hline 9. THYAO & 1,1552 & 9. ARCLK & 1,5467 & 9. SISE & 2.213 .065 \\
\hline 10. AKBNK & 1,1364 & 10. PETKİM & 1,4872 & 10. ARCLK & 1.862 .946 \\
\hline 11. GARAN & 1,1324 & 11. ISCTR & 1,4547 & 11. THYAO & 1.652 .593 \\
\hline 12. EREGL & 1,1085 & 12. THYAO & 1,4410 & 12. EREGL & 1.468 .756 \\
\hline 13. ISCTR & 1,0587 & 13. EREGL & 1,2195 & 13. VAKBN & 1.195 .917 \\
\hline 14. VAKBN & 1,0156 & 14. VAKBN & 1,1394 & 14. PETKİM & 779.653 \\
\hline 15. KCHOL & 0,9653 & 15. KCHOL & 0,8658 & 15. KRDMD & -353.356 \\
\hline 16. SAHOL & 0,9235 & 16. SAHOL & 0,5961 & 16. DOHOL & -1.877 .042 \\
\hline 17. DOHOL & 0,7663 & 17. DOHOL & 0,5938 & 17. KCHOL & -2.816 .054 \\
\hline 18. KRDMD & 0,7483 & 18. KRDMD & 0,5640 & 18. SAHOL & -9.955 .244 \\
\hline
\end{tabular}

2010 yılı analiz sonuçları incelendiğinde, analize dâhil edilen 18 şirketten 14'ünün TQ oranının 1'den yüksek, 4 şirketin ise 1'den düşük olduğu görülmektedir. TQ oranı dikkate alınarak yapılan analiz neticesinde en yüksek performans gösteren 3 şirket sırasıyla; SISE, TTKOM ve YKBNK iken, en düşük performansı gösteren 3 şirket ise sırasıyla; KRDMD, DOHOL ve SAHOL olarak karşımıza çıkmaktadır. TQ oranı 1'den yüksek olan şirketlerin yüksek değerde entelektüel sermayeye sahip oldukları belirlenmiştir. Ayrıca bu şirketlerin, entelektüel sermaye varlıklarından yüksek getiriler elde ettiğini de söylemek mümkündür. Buna karşın TQ oranı 1'den düşük olan şirketlerin entelektüel sermaye değerlerinin düşük olduğu ve varlıkların getiri seviyelerinin yenileme maliyetlerini karşılayamadığı söylenebilir.

PD/DD yöntemi sonucunda elde edilen bulgular incelendiğinde, analize dâhil edilen 18 şirketten 14'ünün PD/DD'nin 1'den yüksek, 4 şirketin ise 1'den düşük olduğu görülmektedir. PD/DD dikkate alınarak yapılan analiz neticesinde en yüksek performansı gösteren 3 şirket sırasıyla; TTKOM, SISE ve YKBNK iken, en düşük performansı gösteren 3 şirket sirasıyla; KRDMD, DOHOL ve SAHOL olarak karşımıza çıkmaktadır. PD/DD 1'den yüksek olan şirketlerin yüksek değerde entelektüel sermayeye sahip oldukları ve entelektüel sermaye varlıklarından yüksek getiriler elde ettiğini söylemek mümkündür. Buna karşın PD/DD 1'den düşük olan şirketlerin ise entelektüel sermaye değerlerinin düşük olduğu ve varlıkların getiri seviyelerinin yenileme maliyetlerini karşılayamadığı da söylenebilir. Diğer taraftan 2010 yılında, TQ ve PD/DD yöntemlerinin genel olarak paralel sonuçlar verdiği görülmektedir.

PD-DD yöntemi doğrultusunda elde edilen bulgular incelendiğinde, analize dâhil edilen 18 şirketten 14'ünün PD-DD'nin pozitif değerler aldığı, 4 şirketin ise negatif değerler aldığ1 görülmektedir. PD-DD dikkate alınarak yapılan analiz neticesinde en yüksek performans1 gösteren 3 şirket sırasıyla; TTKOM, GARAN ve AKBNK iken, en düşük performansı gösteren 3 şirket ise sırasıyla; SAHOL, KCHOL ve DOHOL olarak karşımıza çıkmaktadır. PD-DD arasındaki farkın pozitif olduğu şirketlerde entelektüel sermayeye değerlerinin yüksek olduğu ve entelektüel sermaye varlıklarından yüksek getiriler elde edildiğini söylemek mümkündür. Ancak, PD-DD arasındaki farkın negatif olduğu şirketlerde, entelektüel sermaye değerlerinin düşük olduğu ve bu varlıklardan getiri elde edilemediği söylenebilir. 
Tablo 3: 2011 Yı1ı için Entelektüel Sermaye Değerinin İșletme Bazında Ölçülmesi

\begin{tabular}{|c|c|c|c|c|c|}
\hline Sirketler & TQ & Şirketler & $\underline{\text { PD/DD }}$ & Sirketler & $\frac{\text { PD-DD }}{(\text { Bin TL })}$ \\
\hline 1. TTKOM & 2,1624 & 1. TTKOM & 4,2587 & 1. TTKOM & 18.800 .629 \\
\hline 2. SISE & 2,1563 & 2. SISE & 3,5381 & 2. TCELL & 8.742 .502 \\
\hline 3. TCELL & 1,5099 & 3. TUPRS & 2,2736 & 3. GARAN & 7.203 .181 \\
\hline 4. TUPRS & 1,3802 & 4. TCELL & 1,8100 & 4. AKBNK & 5.948 .621 \\
\hline 5. PETKİM & 1,1001 & 5. HALKB & 1,4323 & 5. TUPRS & 5.611 .110 \\
\hline 6. ARCLK & 1,0526 & 6. GARAN & 1,4098 & 6. HALKB & 3.735 .004 \\
\hline 7. GARAN & 1,0491 & 7. AKBNK & 1,3281 & 7. SISE & 2.657 .825 \\
\hline 8. AKBNK & 1,0425 & 8. PETKİM & 1,1570 & 8. YKBNK & 1.375 .868 \\
\hline 9. HALKB & 1,0410 & 9. YKBNK & 1,1334 & 9. ARCLK & 483.815 \\
\hline 10. YKBNK & 1,0162 & 10. ARCLK & 1,1325 & 10. PETKİM & 267.311 \\
\hline 11. EREGL & 0,9824 & 11. EREGL & 0,9677 & 11. EREGL & -235.548 \\
\hline 12. ISCTR & 0,9813 & 12. ISCTR & 0,8311 & 12. KRDMD & -537.545 \\
\hline 13. VAKBN & 0,9628 & 13. VAKBN & 0,6381 & 13. THYAO & -1.954 .928 \\
\hline 14. SAHOL & 0,9043 & 14. KCHOL & 0,5895 & 14. DOHOL & -2.552 .569 \\
\hline 15. KCHOL & 0,9031 & 15. THYAO & 0,5655 & 15. ISCTR & -3.026 .463 \\
\hline 16. THYAO & 0,8808 & 16. KRDMD & 0,4596 & 16. VAKBN & -3.473 .202 \\
\hline 17. DOHOL & 0,7048 & 17. SAHOL & 0,4325 & 17. KCHOL & -9.552 .823 \\
\hline 18. KRDMD & 0,6833 & 18. DOHOL & 0,3372 & 18. SAHOL & -14.454 .961 \\
\hline
\end{tabular}

2011 yılı analiz sonuçları incelendiğinde, analize dâhil edilen 18 şirketten 10'unun TQ oranının 1 'den yüksek, 8 şirketin ise 1'den düşük olduğu görülmektedir. TQ oranı dikkate alınarak yapılan analiz neticesinde en yüksek performansı gösteren 3 şirket sırasıyla; TTKOM, SISE ve TCELL iken, en düşük performansı gösteren 3 şirket ise KRDMD, DOHOL ve THYAO olarak karşımıza çıkmaktadır. TQ oranı 1'den yüksek olan 10 şirketin yüksek değerde entelektüel sermayeye sahip oldukları belirlenmiştir. Ayrıca bu şirketlerin, entelektüel sermaye varlıklarından yüksek getiriler elde ettiğini de söylemek mümkündür. Buna karşın TQ oranı 1'den düşük olan 8 şirketin entelektüel sermaye değerlerinin düşük olduğu ve varlıkların getiri seviyelerinin yenileme maliyetlerini karşılayamadığı söylenebilir.

PD/DD yöntemi sonucunda elde edilen bulgular incelendiğinde, analize dâhil edilen 18 şirketten 10'unun PD/DD'nin 1'den yüksek, 8 şirketin ise 1'den düşük olduğu görülmektedir. PD/DD dikkate alınarak yapılan analiz neticesinde en yüksek performansı gösteren 3 şirket; TTKOM, SISE ve TUPRS iken, en düşük performansı gösteren 3 şirket ise DOHOL, SAHOL ve KRDMD olarak karşımıza çıkmaktadır. PD/DD 1'den yüksek olan 10 şirketin yüksek değerde entelektüel sermayeye sahip oldukları ve entelektüel sermaye varlıklarından yüksek getiriler elde ettiğini söylemek mümkündür. Buna karşın PD/DD 1'den düşük olan 8 şirketin ise entelektüel sermaye değerlerinin düşük olduğu ve varlıkların getiri seviyelerinin yenileme maliyetlerini karşılayamadığı da söylenebilir. Diğer taraftan 2011 y1lında, 2010 yılında olduğu gibi TQ ve PD/DD yöntemlerinin genel olarak paralel sonuçlar verdiği görülmektedir.

PD-DD yöntemi doğrultusunda elde edilen bulgular incelendiğinde, analize dâhil edilen 18 şirketten 10'unun PD-DD'nin pozitif değerler aldığı, 8 şirketin ise negatif değerler aldığ görülmektedir. PD-DD dikkate alınarak yapılan analiz neticesinde en yüksek performansı gösteren 3 şirket; TTKOM, TCELL ve GARAN iken, en düşük performansı gösteren 3 şirket ise SAHOL, KCHOL ve VAKBN olarak karşımıza çıkmaktadır. PD-DD arasındaki farkın pozitif olduğu şirketlerde entelektüel sermayeye değerlerinin yüksek olduğu ve entelektüel sermaye varlıklarından yüksek getiriler elde edildiğini söylemek mümkündür. Ancak, PD-DD arasındaki farkın negatif olduğu şirketlerde, entelektüel sermaye değerlerinin düşük olduğu ve bu varlıklardan getiri elde edilemediği söylenebilir. 
Tablo 4: 2012 Y11ı için Entelektüel Sermaye Değerinin İșletme Bazında Ölçülmesi

\begin{tabular}{|c|c|c|c|c|c|}
\hline Șirketler & $\underline{T Q}$ & Sirketler & $\underline{\mathrm{PD} / \mathrm{DD}}$ & Sirketler & $\frac{\text { PD-DD }}{(\text { Bin TL })}$ \\
\hline 1. SISE & 2,3779 & 1. SISE & 3,9850 & 1. ТTКОМ & 17.764 .852 \\
\hline 2. ТТКОМ & 2,0324 & 2. TTKOM & 3,7520 & 2. GARAN & 17.250 .815 \\
\hline 3. TCELL & 1,6795 & 3. TUPRS & 2,6376 & 3. AKBNK & 12.724 .232 \\
\hline 4. TUPRS & 1,4810 & 4. ARCLK & 2,0131 & 4. TCELL & 12.675 .067 \\
\hline 5. PETKİM & 1,3950 & 5. TCELL & 1,9953 & 5. HALKB & 9.552 .045 \\
\hline 6. ARCLK & 1,3890 & 6. GARAN & 1,7971 & 6. TUPRS & 8.007 .005 \\
\hline 7. THYAO & 1,1123 & 7. HALKB & 1,7751 & 7. YKBNK & 5.742 .625 \\
\hline 8. GARAN & 1,0960 & 8. PETKİM & 1,6643 & 8. ISCTR & 5.090 .770 \\
\hline 9. HALKB & 1,0882 & 9. AKBNK & 1,5661 & 9. ARCLK & 3.978 .785 \\
\hline 10. AKBNK & 1,0778 & 10. THYAO & 1,3898 & 10.SISE & 3.314 .595 \\
\hline 11. YKBNK & 1,0470 & 11. YKBNK & 1,3406 & 11.THYAO & 2.106 .956 \\
\hline 12. ISCTR & 1,0290 & 12. ISCTR & 1,2241 & 12.PETKİM & 1.105 .683 \\
\hline 13. EREGL & 1,0118 & 13. EREGL & 1,0208 & 13.EREGL & 154.588 \\
\hline 14. VAKBN & 0,9962 & 14. KCHOL & 0,9679 & 14. KRDMD & -385.856 \\
\hline 15. KCHOL & 0,9840 & 15. VAKBN & 0,9670 & 15.VAKBN & -393.154 \\
\hline 16. SAHOL & 0,9388 & 16. KRDMD & 0,6626 & 16. KCHOL & -778.841 \\
\hline 17. KRDMD & 0,8223 & 17. SAHOL & 0,6553 & 17.DOHOL & -1.830 .483 \\
\hline 18. DOHOL & 0,7649 & 18. DOHOL & 0,5518 & 18.SAHOL & -10.517 .085 \\
\hline
\end{tabular}

2012 y1lı analiz sonuçları incelendiğinde, analize dâhil edilen 18 şirketten 13'ünün TQ oranının 1'den yüksek, 5 şirketin ise 1'den düşük olduğu görülmektedir. TQ oranı dikkate alınarak yapılan analiz neticesinde en yüksek performansı gösteren 3 şirket sırasıyla; SISE, TTKOM ve TCELL iken, en düşük performansı gösteren 3 şirket ise DOHOL, KRDMD ve SAHOL olarak karşımıza çıkmaktadır. TQ oranı 1'den yüksek olan 13 şirketin yüksek değerde entelektüel sermayeye sahip oldukları belirlenmiştir. Ayrıca bu şirketlerin, entelektüel sermaye varlıklarından yüksek getiriler elde ettiğini de söylemek mümkündür. Buna karşın TQ oranı 1'den düşük olan 5 şirketin entelektüel sermaye değerlerinin düşük olduğu ve varlıkların getiri seviyelerinin yenileme maliyetlerini karşılayamadığı söylenebilir.

$\mathrm{PD} / \mathrm{DD}$ yöntemi sonucunda elde edilen bulgular incelendiğinde, analize dâhil edilen 18 şirketten 13'ünün PD/DD'nin 1'den yüksek, 5 şirketin ise 1'den düşük olduğu görülmektedir. PD/DD dikkate alınarak yapılan analiz neticesinde en yüksek performansı gösteren 3 şirket; SISE, TTKOM ve TUPRS iken, en düşük performansı gösteren 3 şirket ise DOHOL, SAHOL ve KRDMD olarak karşımıza çıkmaktadır. PD/DD 1'den yüksek olan 13 şirketin yüksek değerde entelektüel sermayeye sahip oldukları ve entelektüel sermaye varlıklarından yüksek getiriler elde ettiğini söylemek mümkündür. Buna karşın PD/DD 1'den düşük olan 5 şirketin ise entelektüel sermaye değerlerinin düşük olduğu ve varlıkların getiri seviyelerinin yenileme maliyetlerini karşılayamadığ 1 da söylenebilir. Diğer taraftan 2012 yılında, 2010 ve 2011 yıllarında olduğu gibi TQ ve PD/DD yöntemlerinin genel olarak paralel sonuçlar verdiği görülmektedir.

PD-DD yöntemi doğrultusunda elde edilen bulgular incelendiğinde, analize dâhil edilen 18 şirketten 13'ünün PD-DD'nin pozitif değerler aldığ 1,5 şirketin ise negatif değerler aldığ1 görülmektedir. PD-DD dikkate alınarak yapılan analiz neticesinde en yüksek performansı gösteren 3 şirket; TTKOM, GARAN, AKBNK ve iken, en düşük performansı gösteren 3 şirket ise SAHOL, DOHOL ve KCHOL olarak karşımıza çıkmaktadır. PD-DD arasındaki farkın pozitif olduğu şirketlerde entelektüel sermayeye değerlerinin yüksek olduğu ve entelektüel sermaye varlıklarından yüksek getiriler elde edildiğini söylemek mümkündür. Ancak, PD-DD arasındaki farkın negatif olduğu şirketlerde, entelektüel sermaye değerlerinin düşük olduğu ve bu varlıklardan getiri elde edilemediği söylenebilir. 
Tablo 5: 2013 Yılı için Entelektüel Sermaye Değerinin İşletme Bazında Ölçülmesi

\begin{tabular}{|c|c|c|c|c|c|}
\hline Sirketler & $\underline{\mathrm{TQ}}$ & Sirketler & $\underline{\mathrm{PD} / \mathrm{DD}}$ & Sirketler & $\frac{\text { PD-DD }}{(\text { Bin TL })}$ \\
\hline $\begin{array}{ll}\text { 1. } & \text { SISE }\end{array}$ & 1,9328 & 1. ТTКОМ & 3,9155 & 1. TTKOM & 15.532 .391 \\
\hline $\begin{array}{ll}\text { 2. } & \text { TTKOM } \\
\end{array}$ & 1,8513 & 2. SISE & 3,2334 & 2. TCELL & 10.259 .198 \\
\hline 3. TCELL & 1,4827 & 3. TUPRS & 2,0907 & 3. GARAN & 6.215 .831 \\
\hline 4. ARCLK & 1,3568 & 4. ARCLK & 1,9837 & 4. TUPRS & 5.604 .470 \\
\hline 5. PETKİM & 1,3150 & 5. TCELL & 1,6974 & 5. AKBNK & 4.665 .021 \\
\hline 6. TUPRS & 1,2651 & 6. PETKİM & 1,5988 & 6. ARCLK & 4.071 .342 \\
\hline 7. THYAO & 1,0758 & 7. THYAO & 1,2764 & 7. SISE & 2.951 .568 \\
\hline 8. GARAN & 1,0281 & 8. GARAN & 1,2701 & 8. THYAO & 1.924 .710 \\
\hline $\begin{array}{ll}\text { 9. } & \text { AKBNK }\end{array}$ & 1,0239 & $\begin{array}{ll}\text { 9. } & \text { AKBNK }\end{array}$ & 1,2108 & 9. HALKB & 1.041 .727 \\
\hline 10. EREGL & 1,0230 & 10. HALKB & 1,0736 & 10. PETKİM & 1.022 .495 \\
\hline 11. HALKB & 1,0074 & 11. EREGL & 1,0371 & 11.EREGL & 323.180 \\
\hline 12. YKBNK & 0,9924 & 12. YKBNK & 0,9343 & 12. KRDMD & -478.184 \\
\hline 13. ISCTR & 0,9874 & 13. ISCTR & 0,8874 & 13. YKBNK & -1.137 .918 \\
\hline 14. VAKBN & 0,9774 & 14. KCHOL & 0,8521 & 14.DOHOL & -2.236 .435 \\
\hline 15. KCHOL & 0,9341 & 15. VAKBN & 0,7570 & 15.ISCTR & -2.654 .256 \\
\hline 16. SAHOL & 0,9304 & 16. KRDMD & 0,6155 & 16. VAKBN & -3.066 .321 \\
\hline 17. KRDMD & 0,8150 & 17. SAHOL & 0,5507 & 17. KCHOL & -3.874 .690 \\
\hline 18. DOHOL & 0,7053 & 18. DOHOL & 0,4410 & 18.SAHOL & -14.385 .567 \\
\hline
\end{tabular}

2013 y1lı analiz sonuçları incelendiğinde, analize dâhil edilen 18 şirketten 11'inin TQ oranının 1'den yüksek, 7 şirketin ise 1'den düşük olduğu görülmektedir. TQ oranı dikkate alınarak yapılan analiz neticesinde en yüksek performansı gösteren 3 şirket sırasıyla; SISE, TTKOM ve TCELL iken, en düşük performansı gösteren 3 şirket ise DOHOL, KRDMD ve SAHOL olarak karşımıza çıkmaktadır. TQ oranı 1'den yüksek olan 11 şirketin yüksek değerde entelektüel sermayeye sahip oldukları belirlenmiştir. Ayrıca bu şirketlerin, entelektüel sermaye varlıklarından yüksek getiriler elde ettiğini de söylemek mümkündür. Buna karşın TQ oranı 1'den düşük olan 7 şirketin entelektüel sermaye değerlerinin düşük olduğu ve varlıkların getiri seviyelerinin yenileme maliyetlerini karşılayamadığı söylenebilir.

PD/DD yöntemi sonucunda elde edilen bulgular incelendiğinde, analize dâhil edilen 18 şirketten 11'inin PD/DD'nin 1'den yüksek, 7 şirketin ise 1'den düşük olduğu görülmektedir. PD/DD dikkate alınarak yapılan analiz neticesinde en yüksek performansı gösteren 3 şirket; TTKOM, SISE ve TUPRS iken, en düşük performansı gösteren 3 şirket ise DOHOL, SAHOL ve KRDMD olarak karşımıza çıkmaktadır. PD/DD 1'den yüksek olan 11 şirketin yüksek değerde entelektüel sermayeye sahip oldukları ve entelektüel sermaye varlıklarından yüksek getiriler elde ettiğini söylemek mümkündür. Buna karşın PD/DD 1'den düşük olan 7 şirketin ise entelektüel sermaye değerlerinin düşük olduğu ve varlıkların getiri seviyelerinin yenileme maliyetlerini karşılayamadığı da söylenebilir. Diğer taraftan 2013 y1lında, önceki yıllarda olduğu gibi TQ ve PD/DD yöntemlerinin genel olarak paralel sonuçlar verdiği görülmektedir.

PD-DD yöntemi doğrultusunda elde edilen bulgular incelendiğinde, analize dâhil edilen 18 şirketten 11'inin PD-DD'nin pozitif değerler aldığı, 7 şirketin ise negatif değerler aldığ görülmektedir. PD-DD dikkate alınarak yapılan analiz neticesinde en yüksek performansı gösteren 3 şirket; TTKOM, TCELL ve GARAN iken, en düşük performansı gösteren 3 şirket ise SAHOL, KCHOL, VAKBN olarak karşımıza çıkmaktadır. PD-DD arasındaki farkın pozitif olduğu şirketlerde entelektüel sermayeye değerlerinin yüksek olduğu ve entelektüel sermaye varlıklarından yüksek getiriler elde edildiğini söylemek mümkündür. Ancak, PD-DD arasındaki farkın negatif olduğu şirketlerde, entelektüel sermaye değerlerinin düşük olduğu ve bu varlıklardan getiri elde edilemediği söylenebilir. 
Tablo 6: 2014 Yı1ı için Entelektüel Sermaye Değerinin İșletme Bazında Ölçülmesi

\begin{tabular}{|c|c|c|c|c|c|}
\hline Sirketler & $\underline{\text { TQ }}$ & Sirketler & $\underline{\mathrm{PD} / \mathrm{DD}}$ & Sirketler & $\begin{array}{l}\text { PD-DD } \\
\underline{(\text { Bin TL })} \\
\end{array}$ \\
\hline 1. SISE & 2,5346 & 1. SISE & 4,0626 & 1. TTKOM & 19.141 .660 \\
\hline 2. TTKOM & 1,9630 & 2. TTKOM & 4,0367 & 2. TCELL & 14.771 .242 \\
\hline 3. TCELL & 1,6241 & 3. ARCLK & 2,3043 & 3. GARAN & 12.936 .931 \\
\hline 4. PETKİM & 1,4664 & 4. TUPRS & 2,2290 & 4. AKBNK & 8.499 .956 \\
\hline 5. ARCLK & 1,4629 & 5. TCELL & 1,8851 & 5. TUPRS & 7.635 .552 \\
\hline 6. $\quad$ TUPRS & 1,3481 & 6. PETKİM & 1,8092 & 6. ARCLK & 5.737 .225 \\
\hline 7. EREGL & 1,3326 & 7. EREGL & 1,5140 & 7. EREGL & 5.299 .693 \\
\hline 8. THYAO & 1,1297 & 8. GARAN & 1,4859 & 8. SISE & 4.664 .853 \\
\hline 9. GARAN & 1,0524 & 9. THYAO & 1,4517 & 9. THYAO & 4.134 .997 \\
\hline 10. AKBNK & 1,0389 & 10. AKBNK & 1,3252 & 10. KCHOL & 2.143 .667 \\
\hline 11. KCHOL & 1,0335 & 11. HALKB & 1,0985 & 11. PETKİM & 1.766 .739 \\
\hline 12. HALKB & 1,0099 & 12. KCHOL & 1,0732 & 12. HALKB & 1.557 .592 \\
\hline 13. YKBNK & 1,0054 & 13. YKBNK & 1,0516 & 13. YKBNK & 1.043 .376 \\
\hline 14. KRDMD & 1,0049 & 14. KRDMD & 1,0111 & 14. KRDMD & 17.494 \\
\hline 15. ISCTR & 0,9950 & 15. ISCTR & 0,9564 & 15. DOHOL & -920.977 \\
\hline 16. VAKBN & 0,9831 & 16. VAKBN & 0,8155 & 16. ISCTR & -1.382 .663 \\
\hline 17. SAHOL & 0,9300 & 17. DOHOL & 0,6835 & 17. VAKBN & -2.760 .523 \\
\hline 18. DOHOL & 0,8661 & 18. SAHOL & 0,5619 & 18. SAHOL & -16.147 .780 \\
\hline
\end{tabular}

2014 y1lı analiz sonuçları incelendiğinde, analize dâhil edilen 18 şirketten 14'ünün TQ oranının 1 'den yüksek, 4 şirketin ise 1'den düşük olduğu görülmektedir. TQ oranı dikkate alınarak yapılan analiz neticesinde en yüksek performansı gösteren 3 şirket sırasıyla; SISE, TTKOM ve TCELL iken, en düşük performansı gösteren 3 şirket ise DOHOL, SAHOL, VAKBN olarak karşımıza çıkmaktadır. TQ oranı 1'den yüksek olan 14 şirketin yüksek değerde entelektüel sermayeye sahip oldukları belirlenmiştir. Ayrıca bu şirketlerin, entelektüel sermaye varlıklarından yüksek getiriler elde ettiğini de söylemek mümkündür. Buna karşın TQ oranı 1'den düşük olan 4 şirketin entelektüel sermaye değerlerinin düşük olduğu ve varlıkların getiri seviyelerinin yenileme maliyetlerini karşılayamadığı söylenebilir.

PD/DD yöntemi sonucunda elde edilen bulgular incelendiğinde, analize dâhil edilen 18 şirketten 14'ünün PD/DD'nin 1'den yüksek, 4 şirketin ise 1'den düşük olduğu görülmektedir. PD/DD dikkate alınarak yapılan analiz neticesinde en yüksek performansı gösteren 3 şirket; SISE, TTKOM ve ARCLK iken, en düşük performans1 gösteren 3 şirket ise SAHOL, DOHOL ve VAKBN olarak karşımıza çıkmaktadır. PD/DD 1'den yüksek olan 14 şirketin yüksek değerde entelektüel sermayeye sahip oldukları ve entelektüel sermaye varlıklarından yüksek getiriler elde ettiğini söylemek mümkündür. Buna karşın PD/DD 1'den düşük olan 4 şirketin ise entelektüel sermaye değerlerinin düşük olduğu ve varlıkların getiri seviyelerinin yenileme maliyetlerini karşılayamadığı da söylenebilir. Diğer taraftan 2014 y1lında, önceki yıllarda olduğu gibi TQ ve PD/DD yöntemlerinin genel olarak paralel sonuçlar verdiği görülmektedir.

PD-DD yöntemi doğrultusunda elde edilen bulgular incelendiğinde, analize dâhil edilen 18 şirketten 14'ünün PD-DD'nin pozitif değerler aldığ 1 , 4 şirketin ise negatif değerler aldığ1 görülmektedir. PD-DD dikkate alınarak yapılan analiz neticesinde en yüksek performansı gösteren 3 şirket; TTKOM, TCELL ve GARAN iken, en düşük performansı gösteren 3 şirket ise SAHOL, VAKBN ve ISCTR olarak karşımıza çıkmaktadır. PD-DD arasındaki farkın pozitif olduğu şirketlerde entelektüel sermayeye değerlerinin yüksek olduğu ve entelektüel sermaye varlıklarından yüksek getiriler elde edildiğini söylemek mümkündür. Ancak, PD-DD arasındaki farkın negatif olduğu şirketlerde, entelektüel sermaye değerlerinin düşük olduğu ve bu varlıklardan getiri elde edilemediği söylenebilir. 
Tablo 7: 2015 Yı11 için Entelektüel Sermaye Değerinin İșletme Bazında Ölçülmesi

\begin{tabular}{|c|c|c|c|c|c|}
\hline Sirketler & $\underline{\text { TQ }}$ & Sirketler & $\underline{\text { PD/DD }}$ & Sirketler & $\frac{\text { PD-DD }}{(\text { Bin TL })}$ \\
\hline 1. SISE & 2,3524 & 1. TTКОМ & 4,3468 & 1. TTKOM & 14.713 .622 \\
\hline 2. TTKOM & 1,7117 & 2. SISE & 3,7520 & 2. TUPRS & 11.131 .699 \\
\hline 3. PETKİM & 1,5702 & 3. TUPRS & 2,7676 & 3. TCELL & 8.874 .041 \\
\hline 4. TUPRS & 1,4838 & 4. ARCLK & 2,1985 & 4. ARCLK & 5.146 .141 \\
\hline 5. ARCLK & 1,4118 & 5. PETKİM & 2,0593 & 5. SISE & 4.445 .583 \\
\hline 6. TCELL & 1,3705 & 6. TCELL & 1,6876 & 6. GARAN & 2.476 .192 \\
\hline 7. GARAN & 1,0095 & 7. GARAN & 1,0903 & 7. PETKİM & 2.361 .117 \\
\hline 8. EREGL & 1,0051 & 8. AKBNK & 1,0303 & 8. AKBNK & 787.996 \\
\hline 9. AKBNK & 1,0034 & 9. EREGL & 1,0083 & 9. EREGL & 87.874 \\
\hline 10. KCHOL & 0,9821 & 10. KCHOL & 0,9592 & 10. KRDMD & -543.616 \\
\hline 11. THYAO & 0,9806 & 11. THYAO & 0,9336 & 11. THYAO & -725.690 \\
\hline 12. HALKB & 0,9792 & 12. HALKB & 0,7930 & 12. KCHOL & -1.177 .743 \\
\hline 13. VAKBN & 0,9692 & 13. YKBNK & 0,6801 & 13. DOHOL & -1.595 .397 \\
\hline 14. YKBNK & 0,9688 & 14. ISCTR & 0,6712 & 14. HALKB & -3.390 .196 \\
\hline 15. ISCTR & 0,9655 & 15. VAKBN & 0,6405 & 15. VAKBN & -5.373 .922 \\
\hline 16. SAHOL & 0,9178 & 16. KRDMD & 0,6100 & 16. YKBNK & -6.727 .178 \\
\hline 17. KRDMD & 0,8496 & 17. DOHOL & 0,4832 & 17. ISCTR & -10.141 .542 \\
\hline 18. DOHOL & 0,7878 & 18. SAHOL & 0,4555 & 18. SAHOL & -20.196 .554 \\
\hline
\end{tabular}

2015 yılı analiz sonuçları incelendiğinde, analize dâhil edilen 18 şirketten 9'unun TQ oranının 1 'den yüksek, 9 şirketin ise 1'den düşük olduğu görülmektedir. TQ oranı dikkate alınarak yapılan analiz neticesinde en yüksek performansı gösteren 3 şirket sırasıyla; SISE, TTKOM ve PETKIM iken, en düşük performansı gösteren 3 şirket ise DOHOL, KRDMD ve SAHOL olarak karşımıza çıkmaktadır. TQ oranı 1'den yüksek olan 9 şirketin yüksek değerde entelektüel sermayeye sahip oldukları belirlenmiştir. Ayrıca bu şirketlerin, entelektüel sermaye varlıklarından yüksek getiriler elde ettiğini de söylemek mümkündür. Buna karşın TQ oranı 1'den düşük olan 9 şirketin entelektüel sermaye değerlerinin düşük olduğu ve varlıkların getiri seviyelerinin yenileme maliyetlerini karşılayamadığı söylenebilir.

PD/DD yöntemi sonucunda elde edilen bulgular incelendiğinde, analize dâhil edilen 18 şirketten 9'unun PD/DD'nin 1'den yüksek, 9 şirketin ise 1'den düşük olduğu görülmektedir. PD/DD dikkate alınarak yapılan analiz neticesinde en yüksek performansı gösteren 3 şirket; TTKOM, SISE ve TUPRS iken, en düşük performansı gösteren 3 şirket ise SAHOL, DOHOL ve KRDMD olarak karşımıza çıkmaktadır. PD/DD 1'den yüksek olan 9 şirketin yüksek değerde entelektüel sermayeye sahip oldukları ve entelektüel sermaye varlıklarından yüksek getiriler elde ettiğini söylemek mümkündür. Buna karşın PD/DD 1'den düşük olan 9 şirketin ise entelektüel sermaye değerlerinin düşük olduğu ve varlıkların getiri seviyelerinin yenileme maliyetlerini karşılayamadığ 1 da söylenebilir. Diğer taraftan 2015 y1lında, önceki yıllarda olduğu gibi TQ ve PD/DD yöntemlerinin genel olarak paralel sonuçlar verdiği görülmektedir.

PD-DD yöntemi doğrultusunda elde edilen bulgular incelendiğinde, analize dâhil edilen 18 şirketten 9'unun PD-DD'nin pozitif değerler aldığ 1,9 şirketin ise negatif değerler aldığı görülmektedir. PD-DD dikkate alınarak yapılan analiz neticesinde en yüksek performansı gösteren 3 şirket; TTKOM, TUPRS ve TCELL iken, en düşük performansı gösteren 3 şirket ise SAHOL, ISCTR ve YKBNK ve olarak karşımıza çıkmaktadır. PD-DD arasındaki farkın pozitif olduğu şirketlerde entelektüel sermayeye değerlerinin yüksek olduğu ve entelektüel sermaye varlıklarından yüksek getiriler elde edildiğini söylemek mümkündür. Ancak, PD-DD arasındaki farkın negatif olduğu şirketlerde, entelektüel sermaye değerlerinin düşük olduğu ve bu varlıklardan getiri elde edilemediği söylenebilir.

Analiz sonuçları, 2010-2015 yılları için ayrı ayrı incelenmiş ve değerlendirilmiştir. Yı1 bazında yapılan bu değerlendirmelere ek olarak yöntem bazında da analiz bulguları aşağıdaki tablolar 
kullanılarak yorumlanmıştır. Bu bağlamda Tablo 8'de Tobin's q Oranı Yöntemi esas alınarak ölçülmüş entelektüel sermaye değerleri gösterilmektedir.

Tablo 8: Tobin's q Oranı Yöntemi Esas Alınarak Ölçülmüş Entelektüel Sermaye Değerleri

\begin{tabular}{|c|c|c|c|c|c|}
\hline \multicolumn{6}{|c|}{ Tobin's q } \\
\hline \multicolumn{2}{|c|}{$\underline{2010}$} & \multicolumn{2}{|c|}{$\underline{2011}$} & \multicolumn{2}{|c|}{$\underline{2012}$} \\
\hline 1. SISE & 2,2687 & 1. TTКОМ & 2,1624 & 1. SISE & 2,3779 \\
\hline 2. ТТКОМ & 2,0977 & 2. SISE & 2,1563 & 2. ТТКОМ & 2,0324 \\
\hline 3. YKBNK & 1,1992 & 3. TCELL & 1,5099 & 3. TCELL & 1,6795 \\
\hline 4. TCELL & 1,9017 & 4. TUPRS & 1,3802 & 4. TUPRS & 1,4810 \\
\hline 5. TUPRS & 1,4142 & 5. PETKİM & 1,1001 & 5. PETKİM & 1,3950 \\
\hline 6. PETKİM & 1,3282 & 6. ARCLK & 1,0526 & 6. ARCLK & 1,3890 \\
\hline 7. ARCLK & 1,2544 & 7. GARAN & 1,0491 & 7. THYAO & 1,1123 \\
\hline 8. HALKB & 1,1224 & 8. AKBNK & 1,0425 & 8. GARAN & 1,0960 \\
\hline 9. THYAO & 1,1552 & 9. HALKB & 1,0410 & 9. HALKB & 1,0882 \\
\hline 10. AKBNK & 1,1364 & 10. YKBNK & 1,0162 & 10. AKBNK & 1,0778 \\
\hline 11. GARAN & 1,1324 & 11. EREGL & 0,9824 & 11. YKBNK & 1,0470 \\
\hline 12. EREGL & 1,1085 & 12. ISCTR & 0,9813 & 12. ISCTR & 1,0290 \\
\hline 13. ISCTR & 1,0587 & 13. VAKBN & 0,9628 & 13. EREGL & 1,0118 \\
\hline 14. VAKBN & 1,0156 & 14. SAHOL & 0,9043 & 14. VAKBN & 0,9962 \\
\hline 15. KCHOL & 0,9653 & 15. KCHOL & 0,9031 & 15. KCHOL & 0,9840 \\
\hline 16. SAHOL & 0,9235 & 16. THYAO & 0,8808 & 16. SAHOL & 0,9388 \\
\hline 17. DOHOL & 0,7663 & 17. DOHOL & 0,7048 & 17. KRDMD & 0,8223 \\
\hline 18. KRDMD & 0,7483 & 18. KRDMD & 0,6833 & 18. DOHOL & 0,7649 \\
\hline \multicolumn{2}{|c|}{$\underline{2013}$} & \multicolumn{2}{|c|}{$\underline{2014}$} & \multicolumn{2}{|c|}{$\underline{2015}$} \\
\hline 1. SISE & 1,9328 & 1. SISE & 2,5346 & 1. SISE & 2,3524 \\
\hline 2. TTKOM & 1,8513 & 2. TTKOM & 1,9630 & 2. TTKOM & 1,7117 \\
\hline 3. TCELL & 1,4827 & 3. TCELL & 1,6241 & 3. PETKİM & 1,5702 \\
\hline 4. ARCLK & 1,3568 & 4. PETKİM & 1,4664 & 4. TUPRS & 1,4838 \\
\hline 5. PETKİM & 1,3150 & 5. ARCLK & 1,4629 & 5. ARCLK & 1,4118 \\
\hline 6. $\quad$ TUPRS & 1,2651 & 6. TUPRS & 1,3481 & 6. TCELL & 1,3705 \\
\hline 7. THYAO & 1,0758 & 7. EREGL & 1,3326 & 7. GARAN & 1,0095 \\
\hline 8. GARAN & 1,0281 & 8. THYAO & 1,1297 & 8. EREGL & 1,0051 \\
\hline 9. $\mathrm{AKBNK}$ & 1,0239 & 9. GARAN & 1,0524 & 9. $\mathrm{AKBNK}$ & 1,0034 \\
\hline 10. EREGL & 1,0230 & 10. AKBNK & 1,0389 & 10. KCHOL & 0,9821 \\
\hline 11. HALKB & 1,0074 & 11. KCHOL & 1,0335 & 11. THYAO & 0,9806 \\
\hline 12. YKBNK & 0,9924 & 12. HALKB & 1,0099 & 12. HALKB & 0,9792 \\
\hline 13. ISCTR & 0,9874 & 13. YKBNK & 1,0054 & 13. VAKBN & 0,9692 \\
\hline 14. VAKBN & 0,9774 & 14. KRDMD & 1,0049 & 14. YKBNK & 0,9688 \\
\hline 15. KCHOL & 0,9341 & 15. ISCTR & 0,9950 & 15. ISCTR & 0,9655 \\
\hline 16. SAHOL & 0,9304 & 16. VAKBN & 0,9831 & 16. SAHOL & 0,9178 \\
\hline 17. KRDMD & 0,8150 & 17. SAHOL & 0,9300 & 17. KRDMD & 0,8496 \\
\hline 18. DOHOL & 0,7053 & 18. DOHOL & 0,8661 & 18. DOHOL & 0,7878 \\
\hline
\end{tabular}

Tobin's q Oranı Yöntemi esas alınarak 6 yıllık analiz dönemi genel olarak incelendiğinde, entelektüel sermaye değeri en yüksek olan şirketler, Türkiye Şişe ve Cam Fabrikaları A.Ş., Türk Telekomünikasyon A.Ş. ve Turkcell İletişim Hizmetleri A.Ş.'dir. Buna karşın ilgili dönemde entelektüel sermaye değeri en düşük olan şirketler ise, Hacı Ömer Sabancı Holding A.Ş., Doğan Şirketler Grubu Holding A.Ş. ve Kardemir Karabük Demir Çelik Sanayi ve Ticaret A.Ş. olarak karşımıza çıkmaktadır. Tobin's q Oranı Yöntemine göre entelektüel sermaye değerleri dikkate alındığında, hizmet ve mali sektörde yer alan şirketlerin (SISE, TTKOM ve TCELL) siralamada en üstlerde yer aldığı ve yüksek düzeyde entelektüel varlığa sahip olduğu söylenebilir. Diğer taraftan 
birçok ortaklığın hisse senetlerinin tamamını ya da büyük bir bölümüne sahip olan ve denetimi altında tutan holdinglerin sıralamada en altlarda yer aldığı ve düşük seviyede entelektüel varlığa sahip olduğunu söylemek mümkündür.

Tablo 9'da Piyasa Değeri / Defter Değeri Yöntemi esas alınarak ölçülmüş entelektüel sermaye değerleri gösterilmektedir.

Tablo 9: Piyasa Değeri / Defter Değeri Yöntemi Esas Alınarak Ölçülmüş Entelektüel Sermaye Değerleri

\begin{tabular}{|c|c|c|c|c|c|}
\hline \multicolumn{6}{|c|}{ Piyasa Değeri / Defter Değeri } \\
\hline \multicolumn{2}{|c|}{2010} & \multicolumn{2}{|l|}{$\underline{2011}$} & \multicolumn{2}{|c|}{$\underline{2012}$} \\
\hline 1. TTKOM & 3,6844 & 1. TTKOM & 4,2587 & 1. SISE & 3,9850 \\
\hline 2. SISE & 3,4628 & 2. SISE & 3,5381 & 2. TTKOM & 3,7520 \\
\hline 3. YKBNK & 2,5554 & 3. TUPRS & 2,2736 & 3. TUPRS & 2,6376 \\
\hline 4. TUPRS & 2,4778 & 4. TCELL & 1,8100 & 4. ARCLK & 2,0131 \\
\hline 5. TCELL & 2,4180 & 5. HALKB & 1,4323 & 5. TCELL & 1,9953 \\
\hline 6. HALKB & 2,1996 & 6. GARAN & 1,4098 & 6. GARAN & 1,7971 \\
\hline 7. GARAN & 1,9988 & 7. AKBNK & 1,3281 & 7. HALKB & 1,7751 \\
\hline 8. AKBNK & 1,9122 & 8. PETKİM & 1,1570 & 8. PETKİM & 1,6643 \\
\hline 9. ARCLK & 1,5467 & 9. YKBNK & 1,1334 & 9. AKBNK & 1,5661 \\
\hline 10. РETKİM & 1,4872 & 10. ARCLK & 1,1325 & 10. THYAO & 1,3898 \\
\hline 11. ISCTR & 1,4547 & 11. EREGL & 0,9677 & 11. YKBNK & 1,3406 \\
\hline 12. THYAO & 1,4410 & 12. ISCTR & 0,8311 & 12. ISCTR & 1,2241 \\
\hline 13. EREGL & 1,2195 & 13. VAKBN & 0,6381 & 13. EREGL & 1,0208 \\
\hline 14. VAKBN & 1,1394 & 14. KCHOL & 0,5895 & 14. KCHOL & 0,9679 \\
\hline 15. KCHOL & 0,8658 & 15. THYAO & 0,5655 & 15. VAKBN & 0,9670 \\
\hline 16. SAHOL & 0,5961 & 16. KRDMD & 0,4596 & 16. KRDMD & 0,6626 \\
\hline 17. DOHOL & 0,5938 & 17. SAHOL & 0,4325 & 17. SAHOL & 0,6553 \\
\hline 18. KRDMD & 0,5640 & 18. DOHOL & 0,3372 & 18. DOHOL & 0,5518 \\
\hline \multicolumn{2}{|c|}{$\underline{2013}$} & \multicolumn{2}{|l|}{$\underline{2014}$} & \multicolumn{2}{|l|}{$\underline{2015}$} \\
\hline 1. ТТКОМ & 3,9155 & 1. SISE & 4,0626 & 1. ТТКОМ & 4,3468 \\
\hline 2. SISE & 3,2334 & 2. TTKOM & 4,0367 & 2. SISE & 3,7520 \\
\hline 3. TUPRS & 2,0907 & 3. ARCLK & 2,3043 & 3. TUPRS & 2,7676 \\
\hline 4. ARCLK & 1,9837 & 4. TUPRS & 2,2290 & 4. ARCLK & 2,1985 \\
\hline 5. TCELL & 1,6974 & 5. TCELL & 1,8851 & 5. PETKİM & 2,0593 \\
\hline 6. PETKİM & 1,5988 & 6. PETKİM & 1,8092 & 6. TCELL & 1,6876 \\
\hline 7. THYAO & 1,2764 & 7. EREGL & 1,5140 & 7. GARAN & 1,0903 \\
\hline 8. GARAN & 1,2701 & 8. GARAN & 1,4859 & 8. AKBNK & 1,0303 \\
\hline 9. AKBNK & 1,2108 & 9. THYAO & 1,4517 & 9. EREGL & 1,0083 \\
\hline 10. HALKB & 1,0736 & 10. AKBNK & 1,3252 & 10. KCHOL & 0,9592 \\
\hline 11. EREGL & 1,0371 & 11. HALKB & 1,0985 & 11. THYAO & 0,9336 \\
\hline 12. YKBNK & 0,9343 & 12. KCHOL & 1,0732 & 12. HALKB & 0,7930 \\
\hline 13. ISCTR & 0,8874 & 13. YKBNK & 1,0516 & 13. YKBNK & 0,6801 \\
\hline 14. KCHOL & 0,8521 & 14. KRDMD & 1,0111 & 14. ISCTR & 0,6712 \\
\hline 15. VAKBN & 0,7570 & 15. ISCTR & 0,9564 & 15. VAKBN & 0,6405 \\
\hline 16. KRDMD & 0,6155 & 16. VAKBN & 0,8155 & 16. KRDMD & 0,6100 \\
\hline 17. SAHOL & 0,5507 & 17. DOHOL & 0,6835 & 17. DOHOL & 0,4832 \\
\hline 18. DOHOL & 0,4410 & 18. SAHOL & 0,5619 & 18. SAHOL & 0,4555 \\
\hline
\end{tabular}

Piyasa Değeri / Defter Değeri Yöntemi esas alınarak analiz dönemi genel olarak değerlendirildiğinde, entelektüel sermaye değeri en yüksek olan şirketler, Türk Telekomünikasyon A.Ş., Türkiye Şişe ve Cam Fabrikaları A.Ş. ve Tüpraş-Türkiye Petrol Rafinerileri A.Ş.'dir. Buna 
karşın ilgili dönemde entelektüel sermaye değeri en düşük olan şirketler ise, Doğan Şirketler Grubu Holding A.Ş., Hacı Ömer Sabancı Holding A.Ş. ve Kardemir Karabük Demir Çelik Sanayi ve Ticaret A.Ş. olarak karşımıza çıkmaktadır. Piyasa Değeri / Defter Değeri yöntemine göre entelektüel sermaye değerleri dikkate alındığında, hizmet, mali ve imalat sektörlerinde yer alan şirketlerin (TTKOM, SISE ve TUPRS) sıralamada en üstlerde yer aldığı ve yüksek düzeyde entelektüel varlığa sahip olduğu söylenebilir. Diğer taraftan Tobin's q Oranı yönteminde olduğu gibi yine holdinglerin sıralamada en altlarda yer aldığı ve düşük seviyede entelektüel varlığa sahip olduğunu söylemek mümkündür.

Tablo 10'da Piyasa Değeri - Defter Değeri Yöntemi esas alınarak ölçülmüş entelektüel sermaye değerleri gösterilmektedir.

Tablo 10: Piyasa Değeri - Defter Değeri Yöntemi Esas Alınarak Ölçülmüş Entelektüel Sermaye Değerleri

\begin{tabular}{|c|c|c|c|c|c|}
\hline \multicolumn{6}{|c|}{$\frac{\text { Piyasa Değeri - Defter Değeri }}{\underline{(B i n ~ T L)}}$} \\
\hline \multicolumn{2}{|c|}{$\underline{2010}$} & \multicolumn{2}{|c|}{2011} & \multicolumn{2}{|c|}{$\underline{2012}$} \\
\hline 1. ТТКОМ & 16.575 .243 & 1. ТТКОМ & 18.800 .629 & 1. TTKOM & 17.764 .852 \\
\hline 2. GARAN & 16.412 .320 & 2. TCELL & 8.742 .502 & 2. GARAN & 17.250 .815 \\
\hline 3. AKBNK & 16.372 .406 & 3. GARAN & 7.203 .181 & 3. AKBNK & 12.724 .232 \\
\hline 4. TCELL & 13.611 .348 & 4. $\mathrm{AKBNK}$ & 5.948 .621 & 4. TCELL & 12.675 .067 \\
\hline 5. YKBNK & 12.859 .302 & 5. TUPRS & 5.611 .110 & 5. HALKB & 9.552 .045 \\
\hline 6. HALKB & 8.930 .320 & 6. HALKB & 3.735 .004 & 6. TUPRS & 8.007 .005 \\
\hline 7. ISCTR & 7.736 .031 & 7. SISE & 2.657 .825 & 7. YKBNK & 5.742 .625 \\
\hline 8. TUPRS & 5.765 .025 & 8. YKBNK & 1.375 .868 & 8. ISCTR & 5.090 .770 \\
\hline 9. SISE & 2.213 .065 & 9. ARCLK & 483.815 & 9. ARCLK & 3.978 .785 \\
\hline 10. ARCLK & 1.862 .946 & 10. PETKİM & 267.311 & 10. SISE & 3.314 .595 \\
\hline 11. THYAO & 1.652 .593 & 11. EREGL & -235.548 & 11. THYAO & 2.106 .956 \\
\hline 12. EREGL & 1.468 .756 & 12. KRDMD & -537.545 & 12. PETKİM & 1.105 .683 \\
\hline 13. VAKBN & 1.195 .917 & 13. THYAO & -1.954 .928 & 13. EREGL & 154.588 \\
\hline 14. PETKİM & 779.653 & 14. DOHOL & -2.552 .569 & 14. KRDMD & -385.856 \\
\hline 15. KRDMD & -353.356 & 15. ISCTR & -3.026 .463 & 15. VAKBN & -393.154 \\
\hline 16. DOHOL & -1.877 .042 & 16. VAKBN & -3.473 .202 & 16. KCHOL & -778.841 \\
\hline 17. KCHOL & -2.816 .054 & 17. KCHOL & -9.552 .823 & 17. DOHOL & -1.830 .483 \\
\hline 18. SAHOL & -9.955 .244 & 18. SAHOL & -14.454 .961 & 18. SAHOL & -0.517 .085 \\
\hline \multicolumn{2}{|c|}{2013} & \multicolumn{2}{|c|}{2014} & \multicolumn{2}{|c|}{$\underline{2015}$} \\
\hline 1. TTKOM & 15.532 .391 & 1. TTKOM & 19.141 .660 & 1. TTКОМ & 14.713 .622 \\
\hline 2. TCELL & 10.259 .198 & 2. TCELL & 14.771 .242 & 2. TUPRS & 11.131 .699 \\
\hline 3. GARAN & 6.215 .831 & 3. GARAN & 12.936 .931 & 3. TCELL & 8.874 .041 \\
\hline 4. TUPRS & 5.604 .470 & 4. $\mathrm{AKBNK}$ & 8.499 .956 & 4. ARCLK & 5.146 .141 \\
\hline 5. AKBNK & 4.665 .021 & 5. TUPRS & 7.635 .552 & 5. SISE & 4.445 .583 \\
\hline 6. ARCLK & 4.071 .342 & 6. ARCLK & 5.737 .225 & 6. GARAN & 2.476 .192 \\
\hline 7. SISE & 2.951 .568 & 7. EREGL & 5.299 .693 & 7. PETKİM & 2.361 .117 \\
\hline 8. THYAO & 1.924 .710 & 8. SISE & 4.664 .853 & 8. AKBNK & 787.996 \\
\hline 9. HALKB & 1.041 .727 & 9. THYAO & 4.134 .997 & 9. EREGL & 87.874 \\
\hline 10. PETKİM & 1.022 .495 & 10. KCHOL & 2.143 .667 & 10. KRDMD & -543.616 \\
\hline 11. EREGL & 323.180 & 11. PETKİM & 1.766 .739 & 11. THYAO & -725.690 \\
\hline 12. KRDMD & -478.184 & 12. HALKB & 1.557 .592 & 12. KCHOL & -1.177 .743 \\
\hline 13. YKBNK & -1.137 .918 & 13. YKBNK & 1.043 .376 & 13. DOHOL & -1.595 .397 \\
\hline 14. DOHOL & -2.236 .435 & 14. KRDMD & 17.494 & 14. HALKB & -3.390 .196 \\
\hline 15. ISCTR & -2.654 .256 & 15. DOHOL & -920.977 & 15. VAKBN & -5.373 .922 \\
\hline 16. VAKBN & -3.066 .321 & 16. ISCTR & -1.382 .663 & 16. YKBNK & -6.727 .178 \\
\hline 17. KCHOL & -3.874 .690 & 17. VAKBN & -2.760 .523 & 17. ISCTR & -0.141 .542 \\
\hline 18. SAHOL & -4.385 .567 & 18. SAHOL & -16.147 .780 & 18. SAHOL & -0.196 .554 \\
\hline
\end{tabular}


Piyasa Değeri - Defter Değeri Yöntemi esas alınarak analiz dönemi genel olarak incelendiğinde, entelektüel sermaye değeri en yüksek olan şirketler, Türk Telekomünikasyon A.Ş., Türkiye Garanti Bankası A.Ş. ve Turkcell İletişim Hizmetleri A.Ş.' dir. Buna karşın ilgili dönemde entelektüel sermaye değeri en düşük olan şirketler ise, Hacı Ömer Sabancı Holding A.Ş. Koç Holding A.Ş. ve Türkiye Vakıflar Bankası T.A.O. olarak karşımıza çıkmaktadır. Piyasa Değeri - Defter Değeri yöntemine göre entelektüel sermaye değerleri dikkate alındığında, hizmet sektöründe yer alan şirketlerin (TTKOM, GARAN ve TCELL) siralamada en üstlerde yer aldığı ve yüksek düzeyde entelektüel varlığa sahip olduğu söylenebilir. Diğer taraftan Tobin's q Oranı ve Piyasa Değeri / Defter Değeri yöntemlerinde de olduğu gibi yine holdinglerin siralamada en altlarda yer aldığı ve düşük seviyede entelektüel varlığa sahip olduğunu söylemek mümkündür.

Analiz bulguları gerek yıl bazında gerek yöntem bazında ele alındığında, entelektüel sermaye değerlerini ortaya koyan Tobin's q Oranı, Piyasa Değeri / Defter Değeri ve Piyasa Değeri - Defter Değeri yöntemlerinin paralel sonuçlar verdiği söylenebilir.

\section{SONUÇ ve DEĞERLENDİRMELER}

Entelektüel sermaye, kara dönüştürülen bilgi olmasının yanı sıra bir şirketin piyasa değeri ile varlıklarının yenileme değeri arasındaki farktır. Şirket içerisindeki maddi olmayan varlıkları ifade eden bu kavram, şirketi yenileştiren ve geliştiren en önemli değer konumundadır. Entelektüel sermaye, insan sermayesi, yapısal sermaye ve müşteri sermayesi unsurlarından oluşmaktadır. Bir şirketin sahip olduğu entelektüel sermaye varlıkları, unsur bazında ölçülebileceği gibi işletme bazında bir bütün olarak da ölçülebilmektedir.

Entelektüel sermayeyi bir bütün olarak şirket bazında ölçebilmek için Tobin's q Oranı, Piyasa Değeri / Defter Değeri ve Piyasa Değeri - Defter Değeri yöntemleri kullanılabilmektedir. Bu yöntemler, şirketlerin finansal verileri doğrultusunda ölçülen ve sayısal olarak ifade edilebilen entelektüel sermaye değerlerini vermektedir. Bu bağlamda Piyasa Değeri - Defter Değeri yöntemi, şirketin piyasa değerinin, defter değerini aşan kısmının tutar olarak entelektüel sermaye değeri olduğu kabul ederken; Piyasa Değeri / Defter Değeri yöntemi ise piyasa değerinin, defter değerini aşan kısmını oransal olarak entelektüel sermaye değeri olarak kabul etmektedir. Tobin's q Oranı yönteminde ise entelektüel sermaye, şirketin sahip olduğu varlıkların piyasa değerinin, bu varlıkları yerine koyma maliyetini aşan kısmı olarak ifade edilmektedir.

Bu çalışmada, entelektüel sermayeyi şirket bazında ölçebilmek için örneklem kümesi Borsa İstanbul Yıldız Pazarı, Ana Pazar, Kolektif Yatırım Ürünleri ve Yapılandırılmış Ürünler Pazarı'nda işlem gören gayrimenkul yatırım ortaklıkları ve girişim sermayesi yatırım ortaklıkları arasından seçilerek oluşturulmuş 30 şirketten oluşan, BİST 30 endeksi kullanılmıştır (www.borsaistanbul.com). BİST 30 endeksi içerisinden analize dâhil edilen 6 bankacılık sektörü, 2 demir çelik sektörü, 4 holding, 2 petrokimya, 2 telekomünikasyon, 1 ulaştırma ve 1 dayanıklı tüketim malları sektörü olmak üzere 18 şirket çalışmaya dâhil edilmiştir.

Çalışmada elde edilen bulgulara göre, Tobin's q Oranı Yöntemi esas alınarak 6 yıllık analiz dönemi genel olarak incelendiğinde, entelektüel sermaye değeri en yüksek olan şirketler, Türkiye Şişe ve Cam Fabrikaları A.Ş., Türk Telekomünikasyon A.Ş. ve Turkcell İletişim Hizmetleri A.Ş.'dir. Buna karşın ilgili dönemde entelektüel sermaye değeri en düşük olan şirketler ise, Hacı Ömer Sabanc1 Holding A.Ş., Doğan Şirketler Grubu Holding A.Ş. ve Kardemir Karabük Demir Çelik Sanayi ve Ticaret A.Ş. olarak belirlenmiştir.

Piyasa Değeri / Defter Değeri Yöntemi esas alınarak analiz dönemi genel olarak değerlendirildiğinde, entelektüel sermaye değeri en yüksek olan şirketler, Türk Telekomünikasyon A.Ş., Türkiye Şişe ve Cam Fabrikaları A.Ş. ve Tüpraş-Türkiye Petrol Rafinerileri A.Ş.'dir. Buna karşın ilgili dönemde entelektüel sermaye değeri en düşük olan şirketler ise, Doğan Şirketler Grubu Holding A.Ş., Hacı Ömer Sabancı Holding A.Ş. ve Kardemir Karabük Demir Çelik Sanayi ve Ticaret A.Ş. olarak tespit edilmiştir. 
Piyasa Değeri - Defter Değeri Yöntemi esas alınarak analiz dönemi genel olarak incelendiğinde ise, entelektüel sermaye değeri en yüksek olan şirketler, Türk Telekomünikasyon A.Ş., Türkiye Garanti Bankası A.Ş. ve Turkcell İletişim Hizmetleri A.Ş.'dir. Buna karşın ilgili dönemde entelektüel sermaye değeri en düşük olan şirketler ise, Hacı Ömer Sabancı Holding A.Ş. Koç Holding A.Ş. ve Türkiye Vakıflar Bankası T.A.O.'dır.

Analizde kullanılan üç yöntemin sonuçları genel olarak değerlendirildiğinde şirketlerin finansal verileri doğrultusunda ölçülen ve sayısal olarak ifade edilebilen entelektüel sermaye değerlerini vermektedir. Analiz bulguları gerek yıl bazında gerek yöntem bazında ele alındığında, entelektüel sermaye değerlerini ortaya koyan Tobin's q Oran1, Piyasa Değeri / Defter Değeri ve Piyasa Değeri Defter Değeri yöntemlerinin paralel sonuçlar verdiği söylenebilir. Analizde kullanılan bu üç yöntemde de en yüksek sonucu veren telekomünikasyon sektöründen Türk Telekomünikasyon A.Ş. ve Turkcell İletişim Hizmetleri A.Ş. şirketleri ve Holding Türkiye Şişe ve Cam Fabrikaları A.Ş şirketi olmuştur. Telekomünikasyon sektöründe faaliyet gösteren bu iki işletmenin 2010 ve 2015 yılları arası faaliyet raporları incelendiğinde, Türk Telekomünikasyon A.Ş. ve Turkcell İletişim Hizmetleri A.Ş.'nin entelektüel sermaye yaratacak unsurlara önem verdiği, özellikle insan sermayesi niteliğini arttırabilmek adına Akademiler kurarak eğitim ve gelişim programları düzenlendiği görülmektedir. Yapısal sermaye unsuru adına organizasyon gelişim faaliyetleri sözleşme ve bütçe yönetimi faaliyetlerini gözlemleyebiliyoruz. Müşteri sermayesini geliştirebilmek için ise müşterin ihtiyaçları doğrultusunda değer yaratabilmek için kazanç ve nitelikler değerlendirilerek müşteriye bir servis olanağ 1 sunmakta ve partner olarak müşteriyle birlikte çalışma ve kazanma faaliyetlerini sürdürmekte olduğu görülmektedir (www.turkcell.com.tr, www.ttyatirimciiliskileri.com.tr).

Türkiye Şişe ve Cam Fabrikaları A.Ş’ye ait yıllık faaliyet raporlarında entelektüel sermaye başlığı diğer iki firmada olduğundan çok daha fazla yer tutmaktadır. Şişe camın entelektüel birikimine katkı sağlamak amacıyla 2012 yılından itibaren müdür ve üst kademe yöneticiler için Şişecam Liderlik Akademisi, 2013 yılında İç Eğitimci Sertifika Programı, ileri seviye UFRS eğitimi faaliyetleri yürütülmüştür. 2014 yılında Laboratuvarda geliştirilerek üretime aktarılan yeni ürünler için patent hazırlık faaliyetleri yapılarak, 2014 yılı içerisinde bir adet Avrupa Patent başvurusu ve iki adet Türk Patent başvurusu tescil ettirilmiştir. Tescillenen patentlerin yanı sıra; 2 adet Türk Patent başvurusu ve 3 adet PCT (Patent Cooperation Treaty) başvurusu gerçekleştirilmiş̧ir. Beş adet Türk ve üç adet PCT patent başvurusu için, TÜBİTAK 1602 Patent Destek Programı'na başvurularak, teşvik alınmıştır. 2015 y1lı içerisinde bir adet Türkiye Faydalı Model ve iki adet Türk Patent başvurusu tescillenmiştir (www.sisecam.com.tr). Türkiye Şişe ve Cam Fabrikaları A.Ş’nin entelektüel sermaye unsurlarına önem verdiği ve insan sermayesi, yapısal sermaye ve müşteri sermayesini bir bütün halinde tutup, yaptığımız analiz sonuçlarını destekler nitelikte uygulamalara sahip olduğunu söyleyebiliriz.

\section{KAYNAKÇA}

ACAR, D., ve DALGAR, H. (2005). Entellektüel Sermayenin Ölçülmesinde Muhasebe Bilgi Sisteminin Katkısı, Muhasebe Ve Denetime Bakış Dergisi, ss.23-40.

ALKAN, G. İ. ve DEMİRELİ, E. (2007). Türkiyede Kullanılan Bazı Şirket Değerleme Yöntemleri ve Bir Uygulama, Dokuz Eylül Üniversitesi Sosyal Bilimler Enstitüsü Dergisi, 9(2): 27-39.

BONTIS, N. (1998). Intellectual Capital: An Exploratory Study That Develops Measures And Models, Management Decision, ss.63-76.

BÖLÜKBAŞI, Y. (2014). Entellektüel Sermayenin İşletme Bazında Ölçülmesinde Kullanılan Yöntemler ve Sigorta Sektöründe Bir Araştırma, Maramara Üniversitesi İ.İ.B. Dergisi, ss.425447.

BREALEY, R. A., MYERS , S. C. ve MARCUS, A. J. (2007). İşletme Finansının Temelleri, (Çev.) Ü. Bozkurt, T. Arıkan ve H. Doğukanlı, Ankara: Literatür Yayıncılık.

CHUNG, K., ve PRUITT, S. W. (1994). A Simple Approximation of Tobin's Q, Financial Management, 70-74. 
ÇETIN, A. (2005). Entellektüel Sermaye ve Ölçülmesi, Marmara Üniversitesi İ.İ.B.F. Dergisi, 10(1): 359-378.

ÇIKRIKÇI, M. ve DAŞTAN, A. (2002). Entellektüel Sermayenin Temel Finansal Tablolar Aracılığıyla Sunulması, Bankacılar Dergisi, (43): 18-32.

DEMIR, Y. ve DEMIREL, E. T. (2011). Rekabet Avantaj1 Yaratmada Entelektüel Sermayenin Önemi, "İşü̈ç" Endüstri İliş̧kileri ve İnsan Kaynakları Dergisi, 13(1): 83-104.

DEY, D. K. ve CHAUHAN, Y. K. (2009). Board Composition And performance in INdian Firms: A Comparision, ICFAI Journal of Corporate Governance, ss.1-19.

ERCAN, M. K. ve ÖZTÜRK, B. (2003). Değere Dayalı Yönetim ve Entelektüel Sermaye. Ankara: Gazi Kitapevi.

Jurczak, J. (2008). Intellectual Capital Measurement Methods, Copyright by Institute of Organization and Managment in Industry, 1(1): 37-45.

KENDİRLİ, S., AKGÜN, Z. ve ÖZÇETİN, N. (2015). Entelektüel Sermayenin Ölçülmesi Ve Frma Değerine Etkileri: Çimento Sektöründe Bir Uygulama, Journal of Economics, Finance and Accounting, 2(4): 533-545.

STEWART, T. A. (1997). Entellektüel Sermaye. (N. Elhüseyin, Çev.) İstanbul: Mess Yayın.

UZAY, Ş. ve SAVAŞ, O. (2003). Entelektüel Sermayenin Ölçülmesi: Mobilyasektöründe Karşilaştirmali Bir Uygulama Örneği, Erciyes Üniversitesi İktisadi ve İdari Bilimler Fakültesi Dergisi, (20): 163-181.

Yıldız, S. (2010). Entellektüel Sermayenin İşletme Performansina Etkisi: Bankacilik Sektöründe Bir Araştirma, Doktora Tezi, Marmara Üniversitesi Sosyal Bilimler Enstitüsü İşletme Anabilim Dalı, İstanbul.

ZOR, İ. ve CENGİZ , S. (2013). Entelektüel Sermaye ile Firma Değeri Arasındaki İlişki:Borsa İstanbul'da Bir Araştırma, Çankırı Karatekin Üniversitesi İktisadi ve İdari Bilimler Fakültesi Dergisi, ss.37-56.

www.borsaistanbul.com.

www.turkcell.com.tr

www.sisecam.com.tr

www.ttyatirimciiliskileri.com.tr 